\title{
Impact of Cognitive Styles on Teaching Language to Representatives of Different Cultures
}

\author{
Ekaterina Andreevna Baranova, ${ }^{1, *}$, Dina Nikolaevna Rubtsova ${ }^{2}$, Nataliya Mikhailovna Rumyantseva ${ }^{2}$, \\ Yulia Alexandrovna Voropaeva ${ }^{3}$, Anna Alexsandrovna Semanina ${ }^{2}$ \\ ${ }^{1}$ Faculty of Philology, Peoples' Friendship University of Russia (RUDN University), Russian Federation \\ ${ }^{2}$ Faculty of Russian Language and General Education, Peoples' Friendship University of Russia (RUDN University), \\ Russian Federation \\ ${ }^{3}$ Institute of Law, Peoples' Friendship University of Russia (RUDN University), Russian Federation
}

Received September 8, 2020; Revised January 4, 2021; Accepted January 20, 2021

\section{Cite This Paper in the following Citation Styles}

(a): [1] Ekaterina Andreevna Baranova, Dina Nikolaevna Rubtsova, Nataliya Mikhailovna Rumyantseva, Yulia Alexandrovna Voropaeva, Anna Alexsandrovna Semanina , "Impact of Cognitive Styles on Teaching Language to Representatives of Different Cultures," Universal Journal of Educational Research, Vol. 9, No. 1, pp. 32 - 36, 2021. DOI: 10.13189/ujer.2021.090104.

(b): Ekaterina Andreevna Baranova, Dina Nikolaevna Rubtsova, Nataliya Mikhailovna Rumyantseva, Yulia Alexandrovna Voropaeva, Anna Alexsandrovna Semanina (2021). Impact of Cognitive Styles on Teaching Language to Representatives of Different Cultures. Universal Journal of Educational Research, 9(1), 32 - 36. DOI: 10.13189/ujer.2021.090104.

Copyright@2021 by authors, all rights reserved. Authors agree that this article remains permanently open access under the terms of the Creative Commons Attribution License 4.0 International License

\begin{abstract}
The study is devoted to the consideration of the possibilities of taking cognitive styles into account when teaching a foreign language to representatives of different cultures. In modern foreign teaching practice, the cognitive style is a fundamental variable of individual differences in the degree of mastery of the material, as well as in the degree of adequate understanding of the teacher's explanations. The study aims to analyze the process of the cognitive functioning of an individual in connection with their behavior and subsequent changes in a certain situation and identify cognitive styles that are directly related to the expression of individual character traits and their relationship with all human properties. As the main method, the authors of the work use an integrated approach that combines the method of psychological observation, cognitive-centered and educational-centered, the questionnaire method, and other empirical methods, using appropriate models and necessary research tools. The results of the study based on the experiment carried out by the authors among foreign students reveal a set of basic cognitive styles with clearly defined characteristics. Knowledge of this system will allow teachers to increase the effectiveness of the learning process and show the most effective methods for introducing and presenting new material in the classroom. The cognitive style allows
\end{abstract}

students from different cultures to be classified according to their preferred way of receiving information (perception or intuitive perception) and their preferred way of processing information and then making decisions (thinking or feeling).

Keywords Cognitive Linguistics, Types of Cognitive Styles, Teaching a Foreign Language, Representatives of Different Cultures

\section{Introduction}

The measure of the individual differences in cognitive styles, where a person stays in relatively constant position is called a cognitive style. These measurements characterize changes in an individual in the form of mental activity. Therefore, they are largely contextually independent of this activity [1, 2].

While the ability to learn a foreign language is built into the structures of consciousness, cognitive styles are the product of deduction. Only empirical measurement can reveal their structures. The total quantity of cognitive styles is hardly defined due to the instability of their 
volume. So, some approaches of cognitive style definition and classification should be regarded more thoroughly.

1. The classical approach in psychology is aimed at a set of cognitive abilities to absorb the information. Only a really big number of observations can be validly used to study a large number of people. Observations correlate with a wider or narrower sample of parameters, which are more strictly defined or "open" but is a priori assumed to be multidimensional.

The "paper and pencil» test based on the choosing of elements can be considered as the method of observation, the most appropriate for that case. In such a test, forms or test books are used in which the tested person writes out the correct answers or marks them, Bennett's mechanical comprehension test, personality questionnaires, etc. This allows a large amount of data to be collected with minimal experimental effort.

The interpretation of the results, initially fragmented, is gradually being grouped. For example, in his study, A. Gehrig proposes to link the construction of the cognitive style with modern theories of cognitive psychology and neurobiology and outlines a structure that brings together conclusions about individual differences in cognition in different disciplines $[3,4]$. The researcher also proposes to characterize the cognitive style as some "patterns of adaptation to the external world that develop based on innate predispositions, the interaction between which is formed by changing environmental requirements" [3]. This taxonomy of cognitive styles allows, according to the researcher, to integrate all well-documented styles of cognition, learning, and decision-making. All of these types of styles correspond to adaptive systems that use different levels of information processing. This approach is intended to promote greater consistency in research and is also more effective in empirical research in education.

Within the framework of this approach, the goal of the researchers is to investigate the mental functioning of an individual in connection with his/her behavior and subsequent changes in a particular situation. If we turn to the consideration of the cognitive-oriented tradition in the historiography of the issue, we can distinguish several models of cognitive functioning which stand at the center of the development of the theory of cognitive style. They include the following areas of research and development which, in our opinion, can be grouped into:

1) activities related to the measurement of style

2) activities related to the verbal-figurative measurement of cognitive style, and

3) recently developed models that reflect a deliberate attempt to integrate both fundamental aspects of cognitive style.

2. Cognitive-centered approach, within which the researchers, led by H. Witkin [5, p. 1127] initially focused on perception since they identified differences in cognitive dynamics when determining the position of a vertical object in space. The bottom line is that the perception of the position of objects in space is based on the joint action of gravitational-vestibular landmarks and visual landmarks, which in normal conditions have consistent, complementary and unambiguous information. Establishing verticality presupposes a distraction from inadequate confusing stimulation and extraction of only a part of adequate relevant information from perceptual integral complexes. Their work is an example of an early study of perception performed by the German Gestalt Psychology School. The result was the transformation of the early rod and frame test for measurement of field dependence was into the pencil and paper test (Embedded Figures Test (EFT)). The Assessment of Cognitive Field Dependence was enlarged by a Group Embedded Figures Test (GEFT). All three tested the ability of subjects to "deflect" the shape from the area around. The theory has been expanded to include several functions related to perception, called psychological differentiation [5, p. 1128].

The cognitive-centered approach also highlights research that measures the impulse-reflection problem. This dimension was originally introduced using the Matching Familiar Figures Test (MFFT) [6, pp. 27-28]. This measurement of cognitive style was, in fact, a continuation of earlier work exploring "conceptual pace" which measured the speed at which a person makes decisions in the face of uncertainty. In the course of the experiments carried out, students were divided into two categories: those who made a quick decision after a brief review of the options which demonstrate a "cognitive-impulsive" type of behavior and those who thought before answering carefully considered all the options which show the "cognitive-reflexive" type of behavior [6, p. 29]. The practical application of the cognitive functioning model is suitable for the tasks related to both academic and non-academic teaching.

Within the framework of the cognitive-centered approach, the model of "convergent-divergent thinking" should also be mentioned. This dimension of intelligence was proposed by J. P. Guildford in 1967 and reflects the way of thinking as well as appropriate strategies for solving problems. The student typically attacks a problem or task by "thinking" in a way that is either open and exploratory or closed and very focused. This theory was further developed in the works of many Russian researchers [7-10] and is important for teaching and learning processes. Moreover, this concept had a significant impact on teaching during the 1970s [11].

The influence of the cognitive-oriented tradition has varied greatly, and most of it has received much criticism for lack of rigor or reliability in verifying empirically obtained data [11]. 
However, all of the above concepts, to one degree or another, are represented in the modern educational-oriented approach. This approach is probably distinguished by three main features: an increased interest in the influence of individual differences and cultural patterns in the teaching process (in particular, a foreign language), the development of new designs and concepts of the teaching style (including foreign language), and the development of an assessment toolkit for empirical verification of the theory of cognitive styles. Within the framework of this approach, three groups of cognitive styles are considered, which reflect the signs of measurement and conceptualization of some firm aspects of studying process.

In our opinion, all of the above models of cognitive styles can be integrated into a learning-oriented approach. Thus, they may be more focused on studying teaching styles than cognitive styles. For modern education, such an integrated approach is very important since in the context of globalization and the growing student exchange, representatives of different cultures make up the course and groups of students, thus being direct participants in the learning process.

The term "teaching style" is often used in a teaching-centered approach. According to P. Willer, "the categorization of groups of styles is based on the definition of common characteristics that may indicate additional fundamental dimensions of the "teaching style" that can be integrated with these dimensions earlier" [6, p. 30].

The penetration of models, terms and meanings in the area of teaching style is increasing with each period of new interest and research cycle. Researchers group the styles in relation to some sources of variability, such as operations and the sequence of mental operations (type and values); structural characteristics of cognitive pictures (Kelly's theory); cognitive aspects of motivation (type and behavior) [11].

Thus, when teaching a foreign language to representatives of different cultures, it should be borne in mind that the cognitive style is an aspect of a more global structure of a psychological type. For assessing the cognitive style, the most common scales are S-N (sensation - intuition) and T-F (thinking - feeling). For example, the Japanese researchers InChan Park and Toshimasa Yamanaka use the S-N scale to represent "information gathering" and the T-F scale to represent "information processing". These two scales give four possible cognitive styles [12, p. 150].

Differentiation of one quality can be considered in different types of behavior, and it can be assumed that there is an implicit connection with cognitive styles based on the MBTI-model.

\section{Methods}

In this context, indicative is an empirical study conducted on the basis of the Faculty of the Russian Language and General Education Disciplines of the Peoples' Friendship University of Russia (RUDN University) (the first year of study) and at the main faculties of the RUDN University (the second and third years of study) in 2019 (April-May), with a sample of 150 foreign students.

The study used the method of questioning. The purpose was to identify the value attitudes of students. The work used such models of empirical research as: MBTI-model, Myers-Briggs Type Indicator, which allow measuring the unique combinations of personal factors of students, to trace the propensity to a certain type of activity, the nature of decisions, style of actions and other individual characteristics that allow students to feel confident and comfortable.

\section{Results}

The study has shown that pursuing each set of values has psychological, practical, and social consequences that may conflict with or may be compatible with other types of values. Sets of values that are close to each other are compatible. For example, the desire to achieve the values of one's own culture may conflict with the desire for the values of benevolence and tolerance for the culture of the host society. The desire for personal success for oneself can make it difficult to take action to improve the performance of those who need help. 


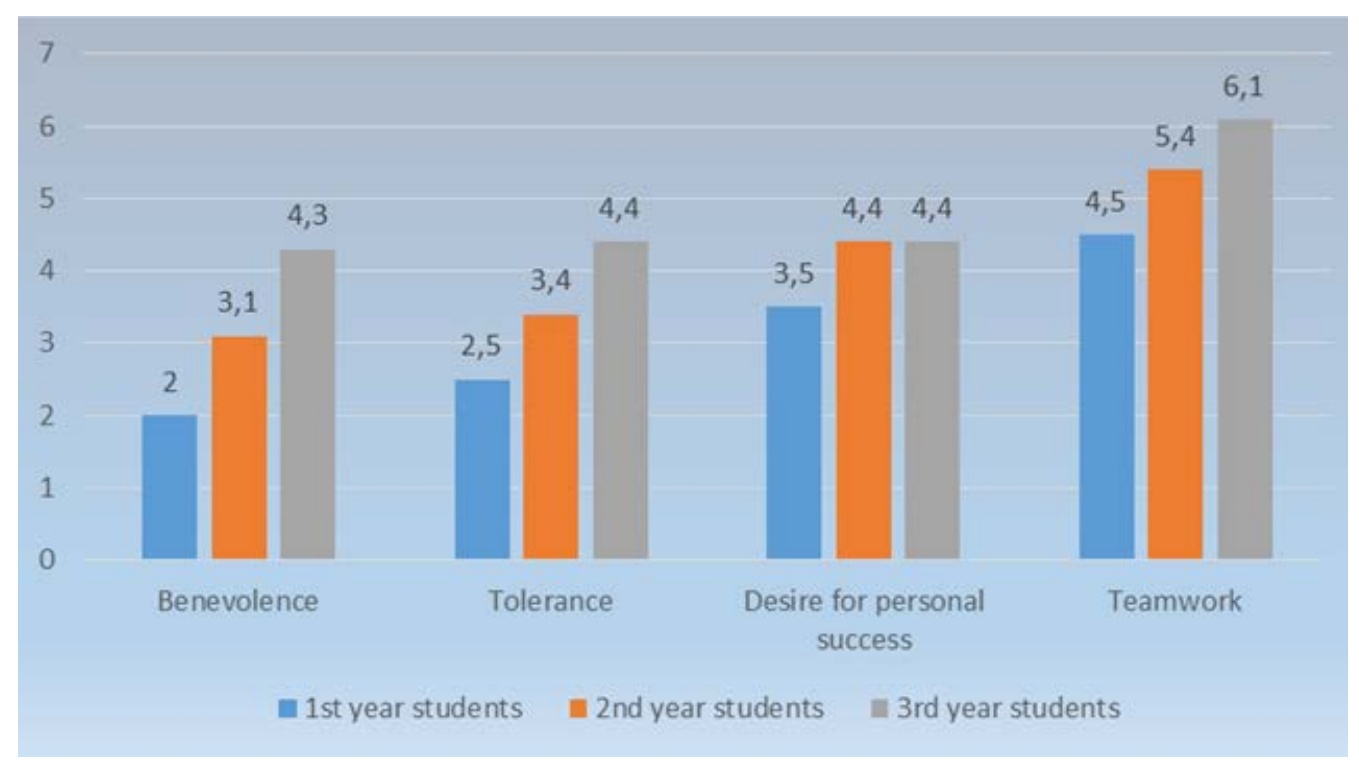

Figure 1. Value attitudes of foreign students 1-3 years of study at the RUDN University

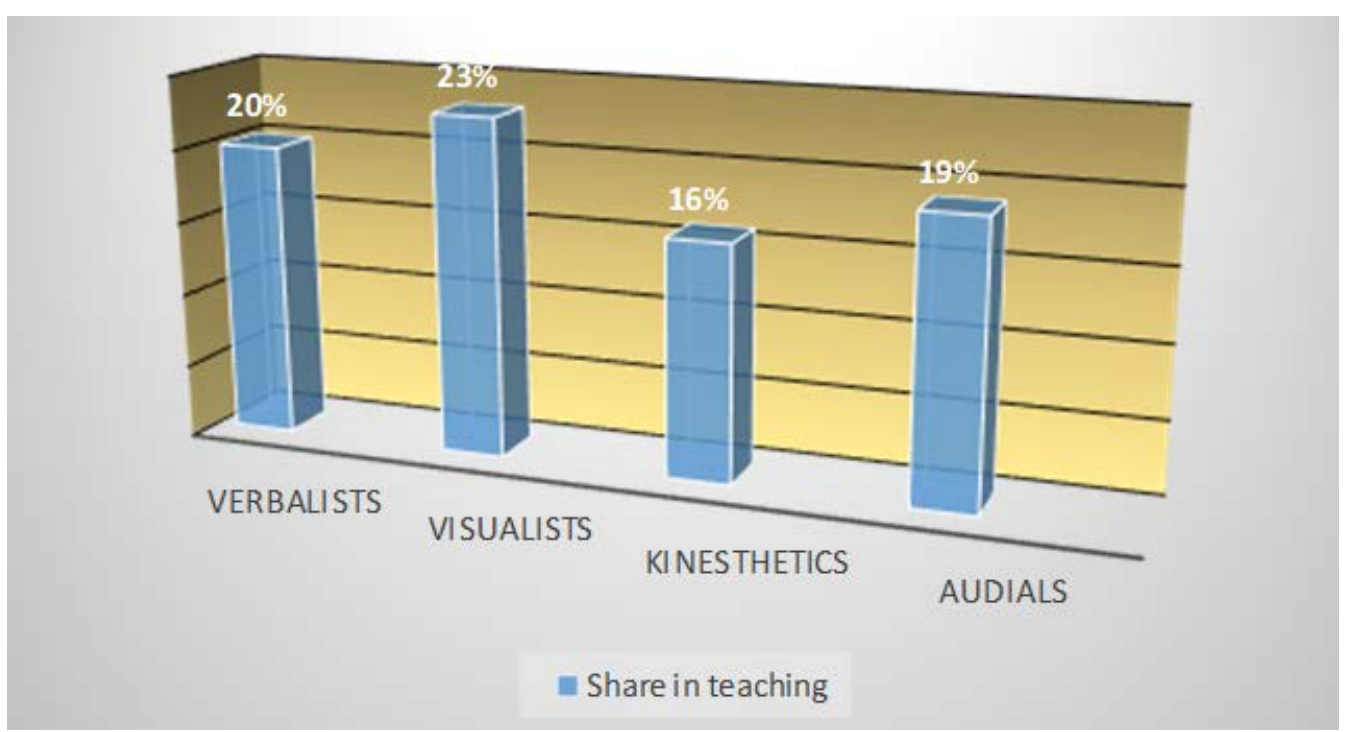

Figure 2. Cognitive styles according to the MBTI-model of foreign students for the 1st-3rd years of study at the RUDN University

As can be seen from the above data obtained by the questionnaire method among students of the 1st-3rd years of study at the RUDN University, the longer the interaction with the host society, the higher the value of such qualities as benevolence, teamwork, and tolerance. At the same time, the desire for personal success does not increase, remaining in the general block of values, but not hindering the growth of the influence of other values in the minds of foreign students as representatives of different cultures. Based on our experiment among foreign students, the following number of cognitive styles with clearly defined characteristics was revealed, which generally correspond to the value series identified by questioning, shown in Figure 1. The main characteristics of cognitive styles in the process of teaching a foreign language (MBTI-model, Myers-Briggs Type Indicator designed to determine one of 16 personality types), identified by us at the empirical level, are presented for clarity in Figure 2.

\section{Discussion}

Thus, the majority of students of the 1st-3rd years of study at the RUDN University are verbalists and visualists by the type of cognitive style. This means that for successful teaching and more effective implementation of curricula for foreign students at the faculties of the RUDN University, it is necessary to maximize verbal and visual methods of work: tasks at seminars in the form of reports in a foreign language and tasks in the form of presentations with audio design so that the format of 
training is more consistent with students' cognitive styles. Methods of work in the form of written assignments and simple translation of the text will not bring the desired effect if the majority of students consist of verbalists and visualists of the cognitive style.

During the experiment, we found that if the carrier of a culture, foreign student, highly values self-overcoming, then the opposite value, self-improvement, will be less appreciated, and vice versa. In the Myers-Briggs model, this makes a lot of sense as it defines the differences between learning and feeling, and thinking and feeling.

However, the initial hypothesis of this empirical study turned out to be erroneous. Most cultures highly value benevolence and a low degree of dependence on others while other values are distributed among them. With the help of such a ranking, one can compare specific cultures with each other to see how different the cognitive styles of students from different cultures (including in the process of learning a foreign language) differ.

In connection with this aspect, a study on the parameters "number $=150$, age $=19-21$ ", based on the model of values, showed that students are more oriented towards the style of "self-improvement and preservation" in comparison with the type of "supranational cultural values". We hypothesize that a new study will show a tendency towards a predominance of the "openness to change" type since the observed types of "self-improvement and preservation" values may be culturally or modally typical of certain cultures. Therefore, we can assume that when interviewing 150 foreign students in the 1st-3rd years of study at the RUDN University, intuition, thinking, and feelings will again be significant for the studied contingent.

\section{Conclusions}

The research has serious impact, since the study of cognitive styles involves the use of a variety of methods and techniques. The related disciplines can be also used variously. The research base in this area can be expanded. In addition to the scientific potential, such studies are of wide practical importance: practicing teachers of foreign languages (including Russian as a foreign language) and related disciplines can improve their understanding the differences among individuals, in group and in organization especially among students from different cultures.

\section{Acknowledgments}

This paper has been supported by the RUDN University Strategic Academic Leadership Program.

\section{REFERENCES}

[1] A. Syamsuddin, D. Juniati, T. Y. E. Siswono. Understanding the Problem Solving Strategy Based on Cognitive Style as a Tool to Investigate Reflective Thinking Process of Prospective Teacher, Universal Journal of Educational Research, Vol. 8, No. 6, 2614-2620, 2020. https://doi.org/1 0.13189/ujer.2020.080644

[2] M. Kartal, Ö. Demir, H. İ. Kaya. An Evaluation on the Regression Level of Prospective Teachers' Metacognitive Skills in terms of their Community Service Activities Perceptions, Universal Journal of Educational Research, Vol. 5, No. 1, 1-10, 2017.https://doi.org/10.13189/ujer.2017.050 101

[3] A. Gehrig. A study of factors affecting cognitive style in Mexican-American children. Dissertations and Theses. Paper 3182. 1982. Available from: https://pdfs.semanticsch olar.org/c33c/65965ca911ffc4bff2d2f5f548a591d64231.pdf

[4] M. Kykalováa, E. A. Vasilyeva. On the problem of categorizing students based on their cognitive styles and teaching strategies, Procedia - Social and Behavioral Sciences, Vol. 176, 578-587, 2015.

[5] H. A. Witkin, D. R. Goodenough, P. Oltman. Psychological differentiation: current status, Journal of Personality and Soc. Psychology, Vol. 37, No. 7, 1127-1145, 1979.

[6] P. Wheeler. The Myers-Briggs Type Indicator and Applications to Accounting Education Research, Issues in Accounting Education, Vol. 16, 26-125, 2001.

[7] D. A. Leontiev. Personal Style and Personal Styles - a look from the 1990s. In: A.V. Libin (ed.) Human Style. Psychological Analysis (pp. 93-109), Infra-M, Moscow, 1998.

[8] A. V. Libin. A Single Concept of a Person's Style: Metaphor or Reality? In: A.V. Libin (ed.) Human Style. Psychological Analysis (pp. 109-124), Infra-M, Moscow, 1998.

[9] O. A. Obdalova, A. V. Soboleva, E. A. Naiman. Cognitive style and its role in individual cognitive sphere in teaching foreign language, Tomsk State University Journal, No. 366, 126-131, 2013.

[10] O. A. Obdalova, A. V. Soboleva. Cognitive style-inclusive teaching a foreign language as a way of individualization of the learning process, Language and Culture, No. 3, 110-115, 2013.

[11] M. Byram, B. Gribkova, H. Starkey. Developing the intercultural dimension in language teaching. a practical introduction for teachers. Council of Europe, Strasbourg, 2002. Available from: https://rm.coe.int/16802fc1c3

[12] I. Park, T. Yamanaka. Cultural Differences of Cognitive Styles According to Experimental Methods- Focused on the Differences of Attribute and Relationship Oriented Thought among Nationalities, Transactions of Japan Society of Kansci Engineering, Vol. 10, No. 2, 149-157, 2011. 